\title{
Pengaruh Personality Traits, Demographic Factor Dan Risk Taking Attitude Terhadap Investment Decision Pada Pengusaha Mikro, Kecil Dan Menengah
}

\author{
Terecia Anabell Makangiras dan Khairina Natsir \\ Program Studi Manajemen Fakultas Ekonomi \\ Universitas Tarumanagara, Jakarta \\ Email: anabellterecia@gmail.com
}

\begin{abstract}
This study examines the impact of Personality Traits, Demographics Factor, and Risk Taking Attitude to Investment Decision Toward Usaha Mikro, Kecil dan Menengah (UMKM). The sample in this study are 100 respondent selected through the purposive sampling method. Sampling techniques using questionnaires online as well as directly. Data processing is done using smart PLS software. The results of this study show that openness to experience has a significant influence on the investment decision. Conscientiousness has a significant influence on investment decision. Demographic factor has no significant influence on investment decision. Meanwhile, risk aversion has a significant influence on investment decision.
\end{abstract}

Keywords: Personality Traits, Demographic Factor, Risk Taking Attitude, Investment Decision.

Abstrak: Tujuan penelitian ini adalah untuk mengetahui pengaruh personality traits, demographic factor, dan risk-taking attitude terhadap investment decision pada pengusaha mikro, kecil dan menengah. Sampel penelitian ini adalah sebanyak 100 responden yang dipilih melalui metode purposive sampling. Teknik pengambilan sampel menggunakan kuesioner secara online maupun secara langsung. Pengolahan data dilakukan dengan menggunakan software smart PLS. Hasil penelitian ini menunjukkan bahwa openness to experience memiliki pengaruh signifikan terhadap investment decision. Conscientiousness memiliki pengaruh signifikan terhadap investment decision. Demographic factor tidak memiliki pengaruh signifikan terhadap investment decision. Sedangkan, risk aversion memiliki pengaruh signifikan terhadap investment decision.

Kata Kunci: Personality Traits, Demographic Factor, Risk Taking Attitude, Investment Decision.

\section{LATAR BELAKANG}

Berdasarkan data dari Badan Pusat Statistik (2019), yang menyatakan bahwa pertumbuhan ekonomi di Indonesia pada tahun 2019 sedang mengalami penurunan. Kepala Badan Perencanaan Pembangunan Nasional (Bappenas) Bambang Brodjonegoro (2019) mengatakan bahwa, "Untuk mengetahui penyebab lambatnya pertumbuhan ekonomi di Indonesia maka dilakukan diagnosa pertumbuhan. Setelah dilakukan diagnosa pertumbuhan tersebut maka ditemukan faktor-faktor yang memperlambat pertumbuhan ekonomi di 
Indonesia yaitu masalah institusi dan regulasi. Yang dimaksud institusi, artinya birokrasi yang telah dilakukan oleh pemerintah dianggap masih belum cukup handal untuk bisa mempermudah investasi di Indonesia."

Menurut Pak and Mahmood (2015) yang mengatakan bahwa, "Keputusan investasi seseorang didasarkan pada faktor demografi (demographics factors) seperti usia, jenis kelamin, penghasilan, tingkat pendidikan, karakteristik pribadi (personality trait) seperti kepribadian, toleransi terhadap risiko, pasar (market) seperti risiko yang telah diperkirakan, tingkat bunga yang diterima, biaya transaksi dan faktor-faktor terkait yang lainnya." Dari sekian banyak model mengenai karakteristik pribadi (personality trait), yang paling sering digunakan ialah Big Five Factor (BFF) model yang mencakup lima dimensi yaitu Openness to experiences, Conscientiousness, Extraversion, Agreeableness, dan Neuroticism yang disingkat menjadi OCEAN.

Menurut Hwang and Lee Cheng (2011) yang menyatakan bahwa, "Investasi biasa didefinisikan sebagai "tindakan atau proses investasi. Sesuatu yang layak dibeli karena mungkin akan menguntungkan di masa depan." Seperti yang kita tahu, investasi tidak hanya menghasilkan keuntungan tetapi juga memiliki risiko yang bermacam-macam sesuai dengan prinsip investasi yaitu "high risk, high return" yang artinya semakin tinggi keuntungan yang didapat maka semakin tinggi juga risiko yang harus ditanggung, begitupun juga sebaliknya semakin rendah keuntungan yang didapat maka semakin rendah juga risiko yang harus ditanggung oleh investor tersebut. Ada banyak sekali jenis-jenis investasi mulai dari saham, obligasi, surat hutang (reksadana), deposito dan sebagainya.

Menurut Sarkar and Sahu (2018) yang menyatakan bahwa, "Faktor demografi (demogaphics factors) tentang investor mencakup jenis kelamin, usia, status perkawinan, pendidikan, pendapatan, pekerjaan, dan sebagainya. Setiap investor sangat unik dalam semua aspek sesuai dengan faktor demografis tersebut. Jadi, ia tidak dapat mengandalkan keputusan yang telah diambil orang lain."Salah satu konsep dasar dari proses pengambilan keputusan adalah konsep risiko (risk). Menurut Zvi Bodie, Alex Kane (2011) yang menyatakan bahwa, "terdapat tiga macam profil risiko seseorang dalam menghadapi suatu risiko", antara lain: risk averse, risk neutral, risk lover.

\section{KAJIAN TEORI}

Openness to Experience. Menurut Martins (2002) yang menyatakan bahwa, "Openness to experience merupakan seseorang yang penuh imajinasi, kreatif, berpandangan luas dan mempunyai banyak akal." Menurut Robie et al. (2005) yang menyatakan bahwa, "Openness to experience juga merupakan seseorang yang berpendidikan dan fleksibel dalam membuat keputusan." Menurut McCrae and Costa (1997) yang menyatakan bahwa, "Seseorang dengan kepribadian openness to experience sering berfantasi dan kadang tampak lebih mengandalkan emosi dalam setiap tindakan yang mereka lakukan."

Conscientiousness. Menurut Gunkel et al., (2010) yang menyatakan bahwa, "Seseorang dengan kepribadian conscientiousness ini memiliki pendirian yang kuat, disiplin, dan memiliki prestasi yang tinggi." Menurut Martins (2002) yang menyatakan bahwa, "Conscientiousness menggambarkan seseorang yang tekun dan dapat dipercaya." Menurut Martins (2002) yang menyatakan bahwa, "Conscientiousness mendeskripsikan seseorang yang dapat dihandalkan, dapat dipercaya, rajin dan tekun." 
Demographic Factor. Menurut Dewey (2003:69) yang menyatakan bahwa, "Pendidikan adalah suatu proses pembentukan kemampuan dasar seseorang secara intelektual dan emosional kearah alam dan sesama manusia." Menurut Elias M Award (1979:4) yang menyatakan bahwa, "... can be defined as an organized group of components (subsystem) linked together according to a plan to achieve a specific objective." Menurut Siagian (2006:273) yang menyatakan bahwa, "Pendidikan adalah proses belajar mengajar mengenai suatu pengetahuan yang dimiliki seseorang dengan standar yang telah ditentukan."

Risk Aversion. Menurut Chitra and Sreedevi (2011) yang menyatakan bahwa, "Risk aversion artinya seorang investor menentang untuk mengambil risiko. Menurut Bodie et al. (2015) yang menyatakan bahwa, "Risk averse, investors who are reject investment portofolio that are fair games or worse." Menurut Agustina (2009) yang menyatakan bahwa, "Risk aversion adalah salah satu tipe investor yang tidak suka menanggung risiko."

Kaitan Openness to Experience Terhadap Investment Decision. Menurut Pak and Mahmood (2015) menyatakan bahwa, "Investor yang memiliki kepribadian openness to experience menunjukkan preferensi yang kuat mengenai sensasi, hal-hal baru dan kompleksitas. Dia dengan mudah menerima informasi pasar yang baru dan mungkin sering kali mengubah portofolio investasi dengan perubahan situasi pasar." Penelitian yang dilakukan oleh Pak and Mahmood (2015) mengatakan bahwa, "Seseorang yang menyukai hal-hal baru dan mempunyai opini pribadi yang kuat lebih bersedia melakukan investasi dengan saham."

Kaitan Conscientiousness Terhadap Investment Decision. Menurut Pak and Mahmood (2015) yang menyatakan bahwa, "Seseorang dengan watak conscientiousness memiliki tingkat keyakinan tertentu, objektif, metodologis, disiplin diri, dan cenderung memiliki tujuan investasi yang jelas." Penelitian yang dilakukan oleh Husnain et al. (2019) mengatakan bahwa, "Seseorang yang memiliki kepribadian conscientiousness akan berinvestasi dalam instrumen keuangan jangka panjang. Sebab seseorang dengan kepribadian conscientiousness sangat berhati-hati, bertanggung jawab dan mereka percaya bahwa dengan adanya persiapan maka kemungkinan mendapatkan keuntungan akan menjadi lebih besar sehingga mereka memilih untuk melakukan investasi keuangan jangka panjang."

Kaitan Demographic Factor Terhadap Investment Decision. Penelitian yang dilakukan oleh Guiso (2015) menemukan bahwa, "Pendidikan, penghasilan, dan kekayaan saling berhubungan dengan investasi di asset yang berisiko. Biasanya wanita memiliki pendapatan yang lebih rendah daripada pria yang artinya akan menghasilkan total kekayaan yang rendah dan biasanya pendidikan wanita lebih sedikit daripada pria."

Kaitan Risk Aversion Terhadap Investment Decision. Beberapa penelitian melaporkan hubungan yang signifikan antara toleransi risiko dan investasi tertentu. Menurut Kuzniak et al. (2015) yang mengatakan bahwa, "Memegang uang tunai dan obligasi secara positif terkait dengan tingkat toleransi risiko yang lebih rendah." Di sisi lain, menurut Bali et al. (2009) yang menyatakan bahwa, "Berinvestasi dalam saham diharapkan akan menghasilkan keuntungan keuangan yang lebih besar dan pertumbuhan modal jangka panjang." Penelitian yang dilakukan oleh Pak and Mahmood (2015) menemukan bahwa, "Dengan adanya pengalaman investasi membuat seseorang lebih menghindari risiko. Hal ini dijelaskan berdasarkan fakta bahwa investor yang memiliki pengalaman negatif dalam berinvestasi di masa lalu menjadi lebih bijaksana dalam membuat keputusan investasi mereka." 


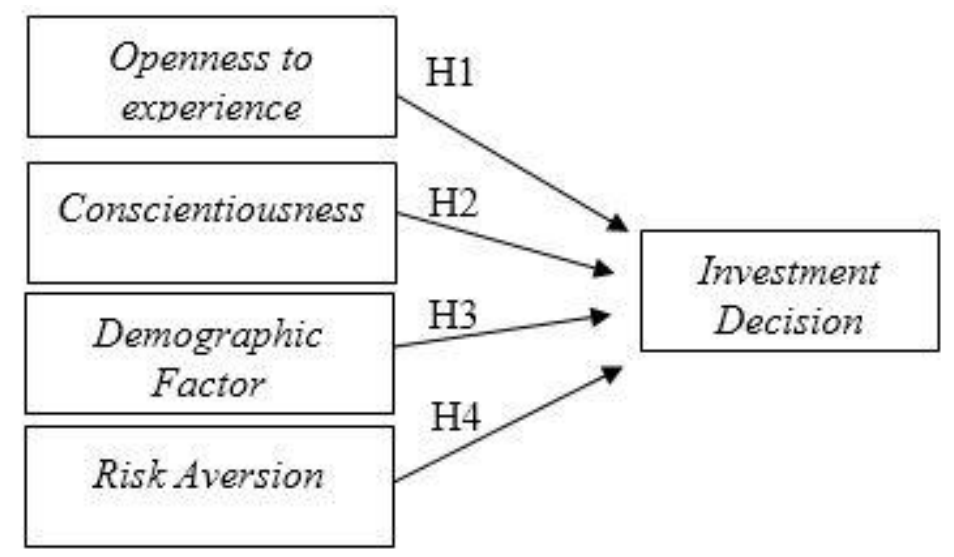

Penelitian ini menggunakan desain penelitian konklusif dengan menggunakan metode penelitian deskriptif. Menurut Travers (1978) yang mengatakan bahwa, "Tujuan dari penelitian deskriptif ini adalah untuk mencerminkan suatu keadaan yang selagi berjalan pada saat penelitian dilaksanakan, dan memeriksa apa saja sebab-sebab dari suatu gejala tertentu." Dalam penelitian ini, peneliti memilih untuk menggunakan non-probability sampling dengan teknik purposive sampling. Menurut Sugiyono (2015:84) yang mengatakan bahwa, "Purposive Sampling adalah teknik penentuan sampel dengan pertimbangan tertentu."

\section{HASIL ANALISIS DATA}

\section{Hasil Validitas Konvergen (AVE: Average Variance Extracted)}

Tabel Hasil AVE: Average Variance Extracted

\begin{tabular}{|c|c|}
\hline Variabel & AVE \\
\hline Conscientiousness & 0,638 \\
\hline Demographic Factor & 1.000 \\
\hline Investment Decision & 0,632 \\
\hline Openness to Experience & 0,594 \\
\hline Risk Aversion & 0,790 \\
\hline
\end{tabular}

Berdasarkan hasil yang diperoleh dalam pengujian nilai AVE (Average Variance Extracted) dapat disimpulkan bahwa variabel conscientiousness, openness to experience, demographic factor, risk aversion dan investment decision menunjukkan bahwa nilai AVE $>0,5$ sehingga seluruh variabel tersebut dapat dinyatakan memenuhi syarat convergent validity. 


\section{Hasil Validitas Diskriminan (HTMT: Heterotrait-Monotrait Ratio)}

Tabel Hasil HTMT: Heterotrait-Monotrait Ratio

\begin{tabular}{|c|c|c|c|c|c|}
\hline & Conscientiousness & $\begin{array}{c}\text { Demographic } \\
\text { Factor }\end{array}$ & $\begin{array}{c}\text { Investment } \\
\text { Decision }\end{array}$ & $\begin{array}{c}\text { Openness to } \\
\text { Experience }\end{array}$ & $\begin{array}{c}\text { Risk } \\
\text { Aversion }\end{array}$ \\
\hline Conscientiousness & & & & & \\
\hline Demographic Factor & 0,113 & & & & \\
\hline Investment Decision & 0,611 & 0,144 & & & \\
\hline $\begin{array}{c}\text { Openness to } \\
\text { Experience }\end{array}$ & 0,646 & 0,096 & 0,843 & & \\
\hline Risk Aversion & 0,250 & 0,049 & 0,830 & 0,752 & \\
\hline
\end{tabular}

Berdasarkan hasil yang diperoleh dalam pengujian HTMT : Heterotrait-Monotrait Ratio dapat disimpulkan bahwa hubungan antara masing-masing variabel terhadap variabel yang lainnya memiliki nilai yang besarnya $<0,85$ sehingga dapat dinyatakan variabel tersebut valid.

\section{Hasil Composite Reliabilty dan Cronbach's Alpha}

Tabel Hasil Composite Reliability dan Cronbach's Alpha

\begin{tabular}{|c|c|c|}
\hline Variabel & Composite Reliability & Cronbach's Alpha \\
\hline Conscientiousness & 0,841 & 0,719 \\
\hline Demographic Factor & 1.000 & 1.000 \\
\hline Investment Decision & 0,836 & 0,710 \\
\hline Openness to Experience & 0,849 & 0,764 \\
\hline Risk Aversion & 0.882 & 0,736 \\
\hline
\end{tabular}

Berdasarkan hasil yang diperoleh dari pengujian composite reliability dapat disimpulkan bahwa variabel conscientiousness, demographic factor, investment decision, openness to experience dan risk aversion memiliki nilai composite reliability yang besarnya $>0,7$ dan juga diperoleh nilai dari cronbach's alpha $>0,7$, dengan ini dapat dinyatakan bahwa seluruh variabel yang digunakan dalam penelitian ini memiliki tingkat reliabilitas yang tinggi.

\section{Hasil $R$ square}

Tabel Hasil Rsquare

\begin{tabular}{|c|c|}
\hline Variabel & $\boldsymbol{R}$ Square \\
\hline Investment Decision & 0,550 \\
\hline
\end{tabular}

Berdasarkan hasil yang diperoleh dari pengujian $R$ square dapat disimpulkan bahwa nilai $R$ square untuk variabel investment decision adalah sebesar 0,550. Dari nilai tersebut dapat dinyatakan bahwa variabel investment decision dapat dijelaskan dengan menggunakan variabel conscientiousness, demographic factor, openness to experience dan risk aversion sebesar 55\% dan sisanya dapat dijelaskan dengan faktor-faktor yang lainnya sebesar $45 \%$.

\section{Hasil Normed Fit Index}


Tabel Hasil Normed Fit Index

\begin{tabular}{|c|c|}
\hline Goodness of Fit & Value \\
\hline Normed Fit Index & 0,604 \\
\hline
\end{tabular}

Berdasarkan hasil yang diperoleh dapat disimpulkan bahwa nilai normed fit index sebesar 0,604 dinyatakan kurang baik dikarenakan nilainya $<0,90$, sedangkan menurut Ghozali (2011:68) yang menyatakan bahwa, "nilai dari normed fit index lebih baik jika nilainya lebih besar dari 0,90 atau sama dengan $0,90 . "$

\section{Hasil Uji t}

Tabel Hasil Uji t

\begin{tabular}{|c|c|c|c|}
\hline Hipotesis & Original Sample & $\boldsymbol{P}$-value & Kesimpulan \\
\hline \begin{tabular}{c} 
H1 $: \begin{array}{c}\text { Openness to Experience >> } \\
\text { Investment Decision }\end{array}$ \\
\hline $\begin{array}{c}\text { H2 }: \text { Conscientiousness >> } \\
\text { Investment Decision }\end{array}$
\end{tabular} Hipotesis Diterima \\
\hline $\begin{array}{c}\text { H3 : Demographic Factor >> } \\
\text { Investment Decision }\end{array}$ & 0,341 & 0,001 & Hipotesis Diterima \\
\hline $\begin{array}{c}\text { H4 : Risk Aversion >> } \\
\text { Investment Decision }\end{array}$ & 0,366 & 0,032 & Hipotesis Ditolak \\
\hline
\end{tabular}

Hasil dari $p$-value menunjukkan bahwa $\mathrm{H} 1$ diterima karena nilai $p$-value $0,001<0,05$ nilai $\alpha$ sehingga dapat dikatakan variabel openness to experience berpengaruh signifikan terhadap variabel investment decision, dan $\mathrm{H} 2$ diterima karena nilai $p$-value $0,032<0,05 \alpha$ sehingga dapat dikatakan variabel conscientiousness berpengaruh signifikan terhadap investment decision, dan $\mathrm{H} 3$ ditolak karena nilai $p$-value $0,358>0,05 \alpha$ sehingga dapat dikatakan variabel demographic factor tidak berpengaruh positif terhadap variabel investment decision dan $\mathrm{H} 4$ diterima karena nilai $p$-value $0,000<0,05 \alpha$ sehingga dapat dikatakan variabel risk aversion berpengaruh signifikan terhadap variabel investment decision.

\section{PENUTUP}

Berdasarkan hasil dari analisis data diatas mengenai pengaruh personality traits, demographic factor dan risk taking attitude terhadap pengusaha mikro kecil dan menengah di sekitar Universitas Tarumanagara, maka dapat disimpulkan berbagai hal sebagai berikut:

1. Personality Traits berpengaruh terhadap Investment Decision Pada Pengusaha Mikro, Kecil dan Menengah.

2. Demographic Factor tidak berpengaruh terhadap Investment Decision Pada Pengusaha Mikro, Kecil dan Menengah.

3. Risk Taking Attitude berpengaruh terhadap Investment Decision Pada Pengusaha Mikro, Kecil dan Menengah. 


\section{DAFTAR PUSTAKA}

Agustina, A. (2009). Profil Kepribadian dan Preferensi Investor dalam Investasi di Aset Finansial. Skripsi : Program S1 Fakultas Ekonomi Universitas Kristen Satya Wacana Salatiga (tidak dipublikasikan).

Awad, Elias M. (1979). System Analysis and Design, Richard D. Irwin, Homewood, Illinois. Bodie, Z., Kane, A., \& Marcus, AJ. (2011). Investments and portofolio Management. Global Edition. New York : The McGraw-Hill Companies,Inc.

Bodie, et al, (2003). Essential of Investments, International Edition, McGrawn-Hill, New York.

Chitra, K., \& Sreedevi, V. R. (2011). Does Personality Traits Influence the Choice of Investment? IUP Journal of Behavioral Finance, 8(2), 47-57.

Dewey, John. et. al. (2003). Dalam Menggugat Pendidikan Fundamentalis. Konservative. Liberal. Anarkis Oleh Paolo Freire. Ivan Illich. Enrich Fromm. dkk. cetakan ke- 4. Alih Bahasa Oleh; Omi Intan Naomi. Yogyakarta; Pustaka Pelajar.

Ghozali, Imam. (2011). “Aplikasi Analisis Multivariate Dengan Program SPSS”. Semarang: Badan Penerbit Universitas Diponegoro. Ghozali, 2014. Aplikasi analisis Multivariate dengan Program SPSS. Badan Penerbit UNDIP, Semarang.

Guiso, Luigi; Jappelli, Tullio and Terlizzese, Daniele. (2015). "Income Risk, Borrowing Constraints, and Portfolio Choice." The American Economic Review, Maret 1996, 86(1), pp. 158-172.

Gunkel, M., Schlaegel, C., Langella, I.A. and Peluchette, J.V. (2010). “Personality and career deciciveness: an international empirical comparison of business students' career planning", Personnel Review, Vol. 39 No. 4, pp. 503-524.

Hwang, Michael S.C and Lee Cheng, Jennifer. F (2011). "Definition of 'Investment' - A Voice from the Eye of the Storm" 1 Asian Journal of International Law 99.

Husnain, Baqir. dkk. (2019). Effect of neuroticism, conscientiousness on investment decisions. Mediation analysis of financial self-efficacy. City University Research Journal. Volume 09 Number 01 January 2019 PP 15-26.

Kuzniak, S., Rabbani, A., Heo, W., Ruiz-Menjivar, J., \& Grable, J. E. (2015). The Grable and Lytton risk-tolerance scale: a 15-year retrospective. Financial Services Review, 24(2), 177-192.

Martins, N. (2002). 'AA model for managing trust', International Journal of Manpower, Vol. 23 No. 8, pp. 754-769

McCrae, R. and Costa, P.T. (1997). "Personality trait structure as a human universal', American Psychologist, Vol. 52 No. 5, pp. 509-516.

Pak, O., \& Mahmood, M. (2015). Impact of personality on risk tolerance and investment decisions: A study on potential investors of Kazakhstan. International Journal of Commerce and Management, 25(4), 370-384.

Robie, C., Brown, D. J., \& Bly, P. R. (2005). The big five in the USA and Japan. Journal of Management Development, 24(8), 720-736.

Sarkar, A. K., \& Sahu, T. N. (2017). Factors influencing behaviour of individual investor in stock market: a case study in West Bengal. International Journal of Commerce and Management Research.

Siagian, Sondang P, (2004). Prinsip-prisip Dasar Manajemen Sumber Daya Manusia, Jilid I, Penerbit Binarupa Aksara, Jakarta.

Sugiyono (2015). Metode Penelitian Kombinasi (Mix Methods). Bandung: Alfabeta. 
Travers, M. W. Robert, (1978). An Introduction to Educational Research, Mac Milan Publising Co, Inc, New York.

Liputan6.com. (2019, 5 Agustus). BPS: Pertumbuhan Ekonomi Kuartal II 2019 Sebesar 5,05 Persen. Diakses pada 14 September 2019, dari https://www.liputan6.com/bisnis/read/4029849/bps-pertumbuhan-ekonomi-kuartal-ii2019-sebesar-505-persen 